\title{
Interface Electronic States and Spin Injection in Fe/GaAs Contacts
}

\author{
S. Honda, J. Inoue, and H. Itoh* \\ Department of Applied Physics, Nagoya University, Furo-cho, Chikusa-ku, Nagoya 464-8603, Japan \\ *Department of Pure and Applied Physics, Kansai University, Yamate-cho, Suita 564-8680, Japan
}

\begin{abstract}
Spin dependence of the conductance, that is, the spin-injection efficiency, of photo-excited electrons has been calculated for $\mathrm{Fe} / \mathrm{GaAs}$ with a Schottky barrier by using a realistic tight-binding model. The conductance calculated by taking $k_{\|}$summation, where $k_{\|}$is the momentum of tunneling electrons parallel to layer planes, has been found to be strongly dependent on the height of the Schottky barrier, and the spin dependence of conductance may change the sign. We found that the latter result is caused by interfacial states near the contact between Fe and GaAs layers.
\end{abstract}

Key words: spin injection, Fe/GaAs contacts, interface electronic states, tight-binding model

\section{$\mathrm{Fe} / \mathrm{GaAs}$ 接合における界面電子状態とスピン注入 \\ 本多周太 , 井上順一郎, 伊藤博介* \\ 名古屋大学大学院工学研究科, 名古屋市千種区不老町 (广 464-8603) \\ *関西大学システム理工学部, 吹田市山手町 (广 564-8680)}

\section{1 はじめに}

スピントロニクスの目標の一つは, 半導体中の電子の持つ電 荷とスピンの自由度を制御することにより，新しいデバイス 原理を構築することである ${ }^{1)}$. 半導体中のスピンを制御する 手法として, 強磁性半導体の作製, 強磁性体 (FM) から半導体 (SC)へのスピン注入，スピン軌道相互作用の利用などがある . 本研究では, FM/SC 接合を介したスピン注入を理論的に取り 扱う. 具体的な物質は $\mathrm{Fe} / \mathrm{GaAs}$ 接合である. FM/SC 接合にお けるスピン注入は , 拡散伝導領域では一般には困難であること が知られている ${ }^{2)}$.これは, 金属強磁性体と半導体の電気伝導 度不整合のためである．この困難は，金属強磁性体と半導体の 間に絶縁層を挿入することで回避できることが示されている． そのような絶縁層として $\mathrm{Al}-\mathrm{O}, \mathrm{MgO}$ などが用いられている. ショットキー障壁も光のような絶縁層の役割を果たす ${ }^{3,4)}$.こ の点を考慮して，数多くの実験がなされ，スピン注入効率の 解析がなされている，一つは，FM/GaAs，FM/AlGaAs-GaAs 接合における量子井戶状態のスピン LED の測定からスピン注 入効率 (電流のスピン分極率 $P$ ) の測定である .この測定では $P \leq 40 \%$ の結果が得られている ${ }^{5-10)}$. また , 絶縁体を挿入し た接合での実験もなされており ${ }^{11-13)}, \mathrm{CoFe} / \mathrm{MgO} / \mathrm{GaAs} に お$ いて最大 $P=52 \%$ の值が得られている ${ }^{13)}$.

他方, 第一原理計算による詳細な理論的研究がなされてい る. Wunnicke らは ${ }^{14,15)}, \mathrm{Fe} / \mathrm{GaAs}$ 接合において, ショット キ一障壁がある場合とない場合におけるコンダクタンスのスピ ン分極率 $P$ を計算した こここで，

$$
P=\left(\Gamma_{\uparrow}-\Gamma_{\downarrow}\right) /\left(\Gamma_{\uparrow}+\Gamma_{\downarrow}\right)
$$

であり， $\Gamma_{\sigma}$ はスピン $\sigma$ のコンダクタンスである .ゼロ電圧極 限では, コンダクタンスのスピン分極率は電流のスピン分極 率と同じであるため, 電流のスピン分極率としても $P$ を用い る.彼らは, わずかに電子ドープされた GaAs を想定し，ゼ
ロ電圧極限における $P$ を, GaAs の伝導帯端 $E_{\mathrm{c}}$ から計った エネルギー，E- $E_{\mathrm{c}}$ の関数として計算している .このスピン 分極率は, 光励起された電子によるスピン注入効率に対応し ている.ショットキー障壁が無い場合には， $E-E_{\mathrm{c}} \sim 0$ にお いて $P \sim 100 \%, E-E_{\mathrm{c}} \gtrsim 0.1 \mathrm{eV} て ゙ P=40-80 \%$ という結 果が得られている.また，ショットキー障壁がある場合には， $k_{\|}=(0,0)$ ( $\bar{\Gamma}$ 点) のみの計算が行われており，ほぼ $100 \%$ の スピン分極率が得られた . なお, $k_{\|}$は入射電子の持つ運動量 の界面に平行な成分である .この高いスピン分極率は, $\mathrm{Fe}$ と $\mathrm{GaAs}$ のバンドの対称性に起因するものである . かれらはこ れを”Symmetry enforced high spin polarization”と呼んでいる この機構は, $\mathrm{Fe} / \mathrm{MgO} / \mathrm{Fe}$ における高トンネル磁気抵抗比と同 じものである ${ }^{16-19)}$.

このような理論的研究は , バリスティック伝導領域において ドープ量の少ない $\mathrm{n}$-型半導体へのスピン注入が効果的に行わ れること，つまり実験において報告されているスピン注入効率 は試料作製手法の向上などによりさらに高めることが可能であ ること, を示唆している．しかしながら, 光励起電子によるス ピン注入においては, フェルミ準位より高いエネルギー領域の 電子状態がトンネル過程に関わる．したがって，ショットキー 障壁がある場合においても， $\bar{\Gamma}$ 点以外の $k_{\|}$が伝導に寄与する 可能性が予想される . 最近では, 光励起電子のトンネル過程に おいてスピン分極率が負となるという実験的報告もある ${ }^{20,21)}$ 光こで, 本研究では, ショットキー障壁のある $\mathrm{Fe} / \mathrm{GaAs}$ 接合 における光励起電子のトンネル過程に対応するコンダクタンス のスピン分極率の計算を行う . 光励起電子のトンネル過程に対 しては, ショットキー障壁の高さが重要な因子となるため, ス ピン分極率のショットキー障壁依存性に着目した計算を行う．

本研究では現実的な tight-binding (TB) 模型を用いる.乥こ で, ショットキー障壁のない場合の計算結果が第一原理計算の 結果を少なくとも半定量的に再現することを確かめたうえで， 


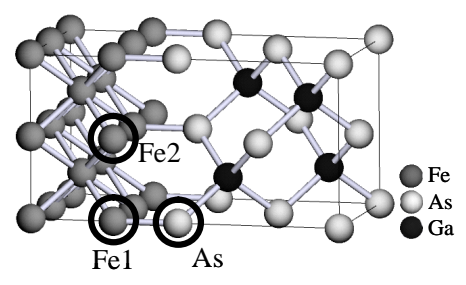

Fig. 1 Model of $\mathrm{Fe} / \mathrm{GaAs}$ junction for As-termination.

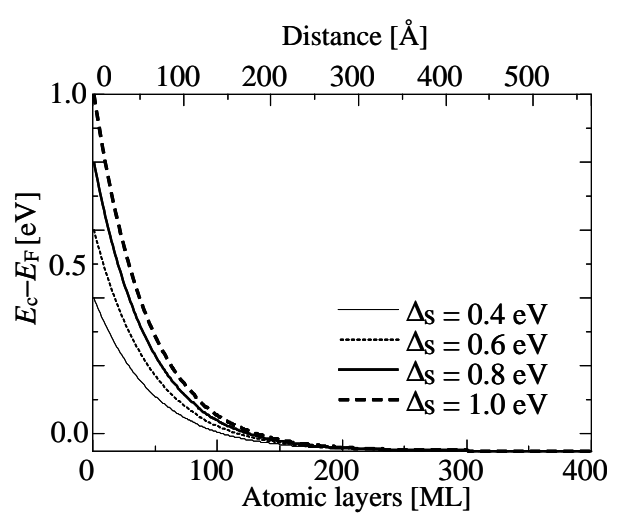

Fig. 2 Spatial dependence of Schottky barrier.

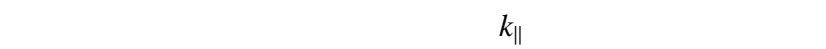
全コンダクタンスの計算を行う，光の結果，ショットキ一障壁 の高さに依存して $P$ の值が大きく变わることが明らかになっ た . また， $P<0$ となる場合も生じることが示される.これは ショットキー障壁内に現れる界面準位のためであることが示さ れる.これらの結果は, Wunnicke ら ${ }^{14,15)}$ の計算結果とは異 なるものである .

\section{2 模型と計算方法}

取り扱う系は半無限の $\mathrm{Fe}$ と半無限の GaAs からなる $\mathrm{Fe} / \mathrm{GaAs}$ 接合である. Fe と GaAs 層は光れ光れ (001) 方向で 積層されたものとする . 接合面は $\mathrm{GaAs}$ が $\mathrm{Ga}$ 原子層と As 原 子層になる場合が考えられる．As 層で Fe と接合する場合，界 面での Fe と GaAs が Fig. 1 のように接合すると仮定する (As 接合)．Ga 層て接合する場合は，GaAs の Ga と As が逆になっ たものを考える (Ga 接合) . 格子の歪みなどの乱れは無いもの とする. また，界面の As と最近接 $\mathrm{Fe}$ の距離は，第一原理バ ンド計算パッケージの VASP を用いた $\mathrm{Fe}_{24}(\mathrm{GaAs})_{12}(001)$ 接

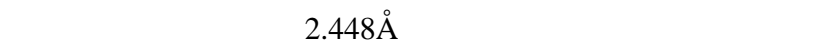
$\mathrm{TB}$ 模型を用いる.このときの，ポテンシャル・飛び移り積分 の Fe のパラメーターは D. A. Papaconstantopoulos ${ }^{22)}$, GaAs はXia et al.のパラメーターを用いる ${ }^{23)}$. また, 界面の飛び移 り積分は $\mathrm{Fe}, \mathrm{GaAs}$ のパラメーターの相乗平均を用いる． $\mathrm{Fe}$ ， $\mathrm{GaAs}$, 界面の飛び移り積分は, 兰れ光れ, 第三近接, 最近接, 第二近接まで取り入れる.

電子状態はリカーシブ・グリーン関数法を用い, コンダク タンスの計算には，線型応答に基づく久保公式を採用する ${ }^{24)}$. 系には乱れを含まないため, 界面に平行方向の波数 $k_{\|}$は保存 され，コンダクタンスは各波数における透過係数の和で与え

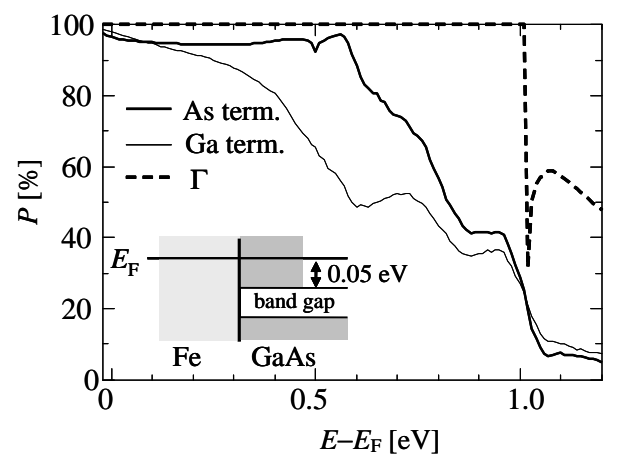

Fig. 3 Calculated results of $P$ for $\mathrm{Fe} / \mathrm{GaAs}$ junctions for As, Ga-termination and $\bar{\Gamma}$ point.

られる.なお計算の便宜上, グリーン関数分母の虚部に微小量 $10^{-10} \mathrm{eV}$ を加える. この結果, 各波数における $10^{-8} e^{2} / h$ 程度 以下のコンダクタンスは数值的に信用できないものとなって いる。

ショットキー障壁が無い場合は, Fe のバルクのフェルミ準 位となるエネルギーを $E_{\mathrm{F}}=0.0 \mathrm{eV}$ とし, $\mathrm{GaAs}$ のバルクの伝 導帯の下端 $E_{\mathrm{c}}$ が $E_{\mathrm{c}}-E_{\mathrm{F}}=-0.05 \mathrm{eV}$ となるように, $\mathrm{GaAs}$ 層 の原子のポテンシャルエネルギーを調整する.ショットキー障 壁を計算に取り入れる場合には, 兴の空間依存性を指数関数 的と仮定して, 界面近傍の GaAs のポテンシャルエネルギー を变更する．Fig. 2 にショットキー障壁の空間依存性を示す． 伝導帯の下端 $E_{\mathrm{c}}$ が界面からの距離 $(\mathrm{GaAs}$ 層厚 ML) の関数と してプロットしている . ML=400 でショットキー障壁の高さ が $0.0001 \mathrm{eV}$ になり，ML > 400 では, ショットキー障壁は消 えるとする . 界面におけるショットキー障壁の高さ $\Delta_{\mathrm{S}}$ は実験 により樣々な値が報告されているので, 本研究では $\Delta_{\mathrm{S}}=0.4$, $0.6,0.8$ および $1.0 \mathrm{eV}$ の值を用いる.なお， GaAs バルクの伝 導帯下端は, ショットキー障壁が無いとき同樣にフェルミ準位 から $0.05 \mathrm{eV}$ 下にとる.

\section{3 計算結果}

以下では, ショットキー障壁の無い場合，ある場合にたいし て光励起された電流に対応するスピン分極率 $P$ の計算を行う. 励起エネルギー $E$ は, フェルミ準位 $E_{\mathrm{F}}$ から測ることとする. ここではバイアス電圧ゼロの極限での計算に限ることとする . 3.1 ショットキー障壁が無い場合

ショットキー障壁のない $\mathrm{Fe} / \mathrm{GaAs}$ 接合系に対して計算され た $P$ を $E-E_{F}$ の関数としてプロットした結果を Fig. 3 に示

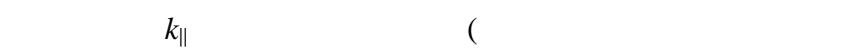
過率の和から求めた) 值であり, 破線は $\bar{\Gamma}$ 点における $P$ の值で ある. $\bar{\Gamma}$ 点における $P$ は, 電子のエネルギーがダウンスピンの $\Delta_{1}$ バンド $(=1.02 \mathrm{eV})$ に達するまでは, $\downarrow$ スピンのコンダクタ ンスが 0 であるため， $P=100 \%$ と大きな值となる.$E$ がレス

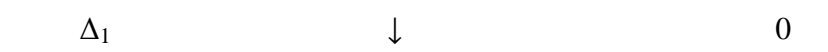

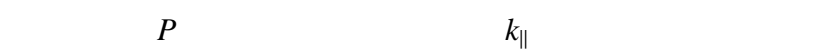
ンダクタンスにおいては, $E-E_{\mathrm{F}}=-0.05 \mathrm{eV} て ゙ は ~ P \sim 100 \%$ であるが, 電子の励起エネルギーが高くなるにつれ， $P$ の値 が減少する. As 接合では, $E-E_{\mathrm{F}}=0.6 \mathrm{eV}$ まで $P \sim 95 \%$ と 


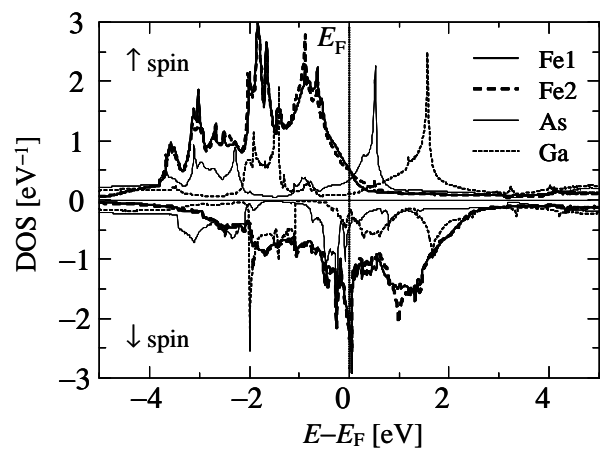

Fig. 4 Electronic density of states for $\mathrm{Fe} 1, \mathrm{Fe} 2$, and As at $\mathrm{Fe} / \mathrm{GaAs}$ contacts for As-termination, and $\mathrm{Ga}$ contact for $\mathrm{Ga}-$ termination.

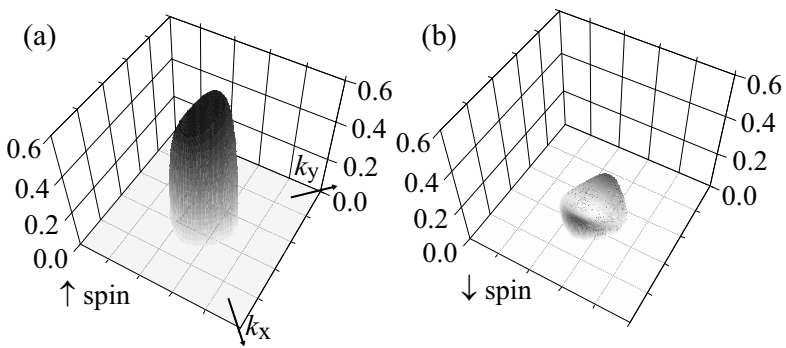

Fig. $5 k_{\|}$resolved conductance at $E-E_{\mathrm{F}}=0.3 \mathrm{eV}$ for $\mathrm{Ga}-$ termination. (a) $\uparrow$ spin and (b) $\downarrow$ spin conductance.

大きな分極率であるが, 弚れ以上 $E-E_{\mathrm{F}}$ が増えると, $P$ は大 きく減少している．また, $\mathrm{Ga}$ 接合では, $E-E_{\mathrm{F}}$ が $-0.05 \mathrm{eV}$ から増えるにつれて, $P$ が減少している．これら $P$ の減少は, $E-E_{\mathrm{F}}=-0.05 \mathrm{eV}$ では $\Gamma$ 点しか伝導に寄与しないが, 高エネ ルギーとなるにつれて $\bar{\Gamma}$ 点以外の状態が伝導に寄与するため である.なお，これらの結果は, Wunnicke らの計算結果と半 定量的に一致しており, 本研究で用いた TB 模型の妥当性を示 すものとなっている .

Fig. 4 は接合界面の電子状態の計算結果である .ここで, 太 い実線は As 接合における Fe1 原子, 太い波線は Fe2 原子, 細 い実線は As 原子，細い波線は Ga 接合における界面 $\mathrm{Ga}$ 原子位 置での電子の状態密度である. As 接合と $\mathrm{Ga}$ 接合とで, $\mathrm{Fe} の$ 界面における状態密度はほとんど变化しない， $E_{\mathrm{F}}$ 近傍では, $\downarrow$

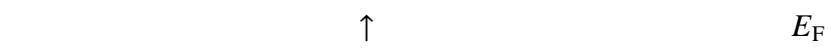
近傍での高いレスピン電子状態は Fe の界面状態である . 計算 で得られた非常に高いスピン分極率は, 状態密度模型からは理 解できないことがわかる .

Fig. 5 に Ga 接合における $E-E_{\mathrm{F}}=0.3 \mathrm{eV}$ での各スピンの コンダクタンスを界面平行方向の波数で分解した図を示す.$k_{x}$ 軸, $k_{y}$ 軸のなす面の中心が $\bar{\Gamma}$ 点である . また, $\bar{\Gamma}$ 点周りの状態 を確認するために, $\bar{\Gamma}$ 点を中心ブリルアルゾーンの $1 / 2$ を拡大 表示した .このエネルギーにおいては, $\mathrm{GaAs}$ バルクの電子の 状態が $\bar{\Gamma}$ 点周りにしかないため, グラフに表示していない波 数でのコンダクタンスは 0 である.个スピン電子に対しては， $\bar{\Gamma}$ 点でのコンダクタンスは非常に高いが , $\bar{\Gamma}$ 点から外れるにつ れてコンダクタンスは減少する。また, GaAs の状態が無い波

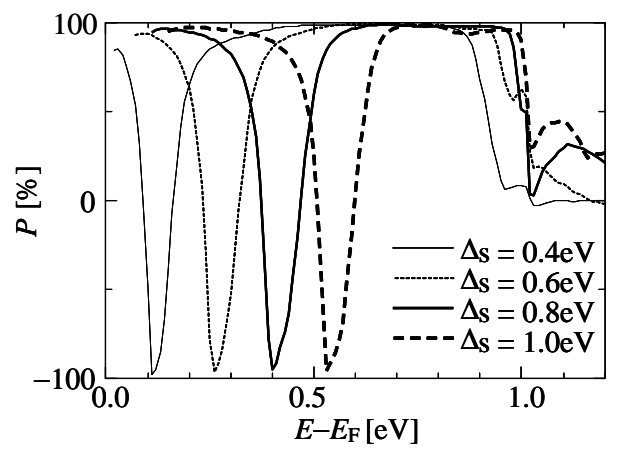

Fig. 6 Calculated results of $P$ for $\mathrm{Fe} / \mathrm{GaAs}$ junctions with Schottky barrier. $\Delta_{\mathrm{S}}=0.4,0.6,0.8$, and $1.0 \mathrm{eV}$.

数になると，コンダクタンスは 0 になる .」スピン電子では, 「点のコンダクタンスは 0 である . しかし , 全体としてコン ダクタンスは小さいものの, $\bar{\Gamma}$ 点から少し外れた場所にピーク 構造を持つ.この $\bar{\Gamma}$ 点以外の伝導の影響で, 分極率 $P$ が減少 している .これらの結果も Wunnicke らの計算結果と同じであ り，彼らの提唱する”Symmetry enforced high spin polarization” となっている.

3.2 ショットキー障壁のある場合

ショットキー障壁を取り入れた $\mathrm{Fe} / \mathrm{GaAs}$ 接合系における 分極率 $P$ の計算結果を $E-E_{\mathrm{F}}$ の関数として Fig. 6 に示す. ショットキー障壁の大きさとして $, \Delta_{\mathrm{S}}=0.4,0.6,0.8,1.0 \mathrm{eV}$ を用い, 界面の接合は As 接合である . 各 $\Delta_{\mathrm{S}}$ で $P \sim-100 \%$ と なる負のピークができているのがわかる . 負のピーク以外の工 ネルギーでは $P \sim 100 \%$ となっている . 接合界面を Ga 接合に すると，負のピークは $\Delta_{\mathrm{S}}=0.8,1.0 \mathrm{eV}$ において，弚れ光れ $E-E_{\mathrm{F}}=0.12,0.25 \mathrm{eV}$ に形成される. $\Delta_{\mathrm{S}}=0.4,0.6 \mathrm{eV}$ にお いては, 負のピークは $E-E_{\mathrm{F}}<0.05 \mathrm{eV}$ で形成されると考えら れるが, GaAs のバンドギャップに相当するエネルギーになる ため，確認できない．また，As 接合で $\Delta_{\mathrm{S}}$ を固定し，ショット キー障壁の厚さを倍 $(\mathrm{ML}=800)$, 半分 $(\mathrm{ML}=200)$ とした場合 にも，ほぼ同じエネルギーで負のピークが観測される．なお， $\mathrm{ML}=800$ ではピークは鋭くなり, $\mathrm{ML}=400$ では緩やかになる . さらに, GaAs の伝導帯のバンドの下端を $E_{\mathrm{c}}-E_{\mathrm{F}}=-0.01$, $-0.15 \mathrm{eV}$ とした場合もほとんど同じエネルギーで負のピーク が形成される . したがって, 界面の電子状態が負のピークに大 きく影響していると考えられる . なお, 図には示されていない が, $\bar{\Gamma}$ 点における分極率は, ショットキー障壁の高さ , 厚さに 寄らず $P \sim 100 \%$ となることが確認されている .

$P<0$ となるエネルギー領域が現れる理由を調べるため に，波数分解したコンダクタンスと界面状態密度を計算する. $E-E_{\mathrm{F}}=0.4 \mathrm{eV}, \Delta_{\mathrm{S}}=0.8 \mathrm{eV}$ における各スピンの波数分解し たコンダクタンスを Fig. 7 に示す. 表示範囲は Fig. 5 と同じ である.ショットキー障壁が無い場合同樣，个スピン電子のコ ンダクタンスは $\bar{\Gamma}$ 点で最大值を持っている .」スピンのコンダ

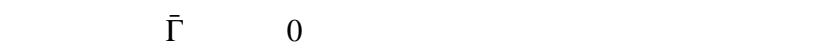

Fig. 8 に, $E-E_{\mathrm{F}}=0.4 \mathrm{eV}, \Delta_{\mathrm{S}}=0.8 \mathrm{eV}$ における, 波数分解 した界面層の電子状態を示す . (a)が个スピン , (b)がレスピン の状態密度である . (b) は $\bar{\Gamma}$ 点の状態が見やすいように紙面手 


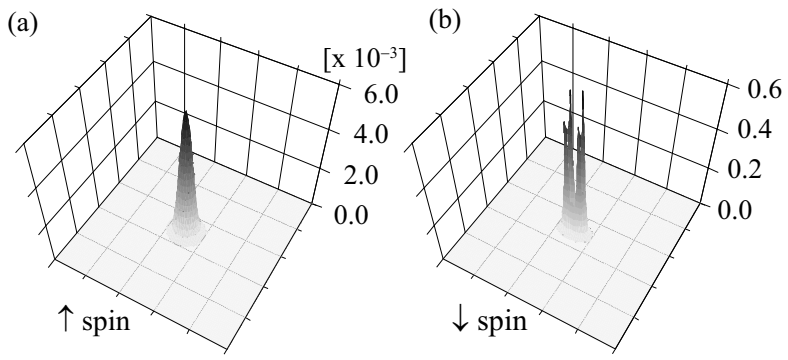

Fig. $7 k_{\|}$resolved conductance for As-termination with $\Delta_{\mathrm{S}}=$ $0.8 \mathrm{eV}$ at $E-E_{\mathrm{F}}=0.4 \mathrm{eV}$. (a) $\uparrow$ spin conductance, (b) $\downarrow$ spin conductance.
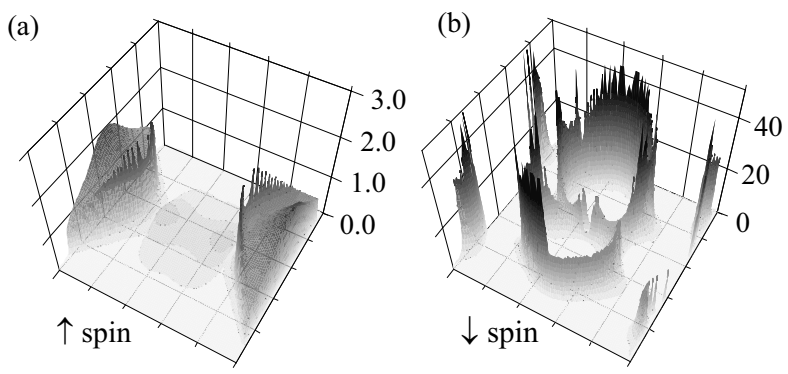

Fig. $8 k_{\|}$resolved density of states at interfacial As site with $\Delta_{\mathrm{S}}=0.8 \mathrm{eV}$ at $E-E_{\mathrm{F}}=0.4 \mathrm{eV}$. (a) $\uparrow$ spin state, (b) $\downarrow$ spin state.

前側 $1 / 4$ の高いピークを半分に減らしている. 表示範囲は Fig. 7 と同じである.个スピンは $\bar{\Gamma}$ 点周りにほとんど状態が無く， $\bar{\Gamma}$ 点から離れると幅の広い山型の状態がある．しかし，GaAs のバルクは $\bar{\Gamma}$ 点周りにしか状態がないため, この山型の状態 は伝導には寄与しない . したがって , 个スピンの伝導はショッ トキー障壁によるトンネル伝導となり, コンダクタンスが大き く減少する.」スピンのピークは8の字型で $\bar{\Gamma}$ 点を中心に形成 されている.この状態は界面状態といえる．この状態の $\bar{\Gamma}$ 点 近傍は, $s, p_{z}$ 軌道電子から形成されており，周辺は, $p_{x}, p_{y}$ 軌道の電子から形成されている. 界面垂直方向に手を伸ばした $p_{z}$ 軌道の電子と異方性の無い $s$ 軌道の電子が, 界面垂直方向 の伝導にはよく寄与すると考えられるため, $\bar{\Gamma}$ 点近傍の状態に より, スピンのコンダクタンスが大きくなる .

$$
4 \text { まとめ }
$$

ショットキー障壁が存在する $\mathrm{Fe} / \mathrm{GaAs}$ 接合における光励起 電子に対するスピン注入効率 (コンダクタンスのスピン分極率) を現実的な tight-binding(TB) 模型を用いて計算した . ショッ トキー障壁がない場合の計算結果は, 第一原理計算の結果を半 定量的に再現するものであり，本計算手法の妥当性を示すもの となっている. ショットキー障壁のある場合, 光励起電子がも たらすスピン分極率の計算結果は, ショットキー障壁に大きく 依存すること, あるエネルギー領域ではスピン分極率が負の值 をとることが示された .これらの結果は, ショットキー障壁内 に形成される界面状態によることが明らかにされた . この点 は，これまでの計算では見逃されていた点である．

絶縁体，例えば $\mathrm{MgO}$ 層を挿入した場合，大きなスピン分極
率が期待される . また , 界面の乱れも大きな影響を与え光うで ある ${ }^{19,25)}$. これらの効果およびスピン分極率のバイアス電圧 依存性については今後計算を行う予定である .

謝辞

この研究を行うにあたり，科学研究費・特定領域研究シリコ ンナノエレクトロニクスの新展開, スピン流の創出と制御, 次 世代スーパーコンピュータプロジェクト・ナノサイエンスプロ グラム , 21 世紀 COE プログラム” 計算科学フロンティア” に感謝いたします．

\section{References}

1) H. Ohno, Science 281, 951 (1998).

2) G. Schmidt, D. Ferrand, L. W. Molenkamp, A. T. Filip, and B. J. van Wees, Phys. Rev. B 62, R4790 (2000).

3) E. I. Rashba, Phys. Rev. B 62, R16267 (2000).

4) A. Fert and H. Jaffres, Phys. Rev. B 64, 184420 (2001).

5) O. M. J. van't Erve, G. Kioseoglou, A. T. Hanbicki, C. H. Li, B. T. Jonker, R. Mallory, M. Yasar, and A. Petrou, App. Phy. Lett. 84, 4334 (2004).

6) A. T. Hanbicki, B. T. Jonker, G. Itskos, G. Kioseoglou, A. Petrou, App. Phy. Lett. 80, 1240 (2002).

7) A. T. Hanbicki, O. M. J. van't Erve, R. Magno. G. Kioseoglou, C. H. Li, B. T. Jonker, G. Itskos, R. Mallory, M. Yasar, and A. Petrou, App. Phy. Lett. 82, 4092 (2003).

8) S. E. Andresen, S. J. Steinmuller, A. Ionescu, G. Wastlbauer, C. M. Guertler, and J. A. C. Bland, Phy. Rev. B 68, 073303 (2003).

9) S. J. Steinmuller, C. M. Gürtler, G. Wastlbauer, and J. A. C. Bland, Phy. Rev. B 72, 045301 (2005).

10) C. Adelmann, X. Lou, J. Strand, C. J. Palmstrøm, and P. A. Crowell, Phy. Rev. B 71, 121301(R) (2005).

11) V. F. Motsnyi, J. De Boeck, J. Das, W. Van Roy, G. Borghs, E. Goovaerts, and V. I. Safarov, App. Phy. Lett. 81, 265 (2002).

12) T. Manago and H. Akinaga, App. Phy. Lett. 81, 694 (2002)

13) X. Jiang, R. Wang, R. M. Shelby, R. M. Macfarlane, S. R. Bank, J. S. Harris, and S. S. P. Parkin, Phy. Rev. Lett. 94, 056601 (2005).

14) O. Wunnicke, Ph. Mavropoulos, R. Zeller, P. H. Dederichs, and D. Grundler, Phys. Rev. B 65, 241306(R) (2002).

15) O. Wunnicke, Ph. Mavropoulos, R. Zeller, and P. H. Dederichs, J. Phy: Cond. Matt. 16, 4643 (2004).

16) W. H. Butler, X.-G. Zhang, T. C. Schulthess, and J. M. MacLaren, Phys. Rev. B 63, 54416 (2001).

17) J. Mathon and A. Umerski, Phys. Rev. B 63, 220403 (2001).

18) S. Yuasa, T. Nagahama, A. Fukushima, Y. Suzuki, and K. Ando, Nat. Mater. 3, 868 (2004).

19) H. Itoh and J. Inoue, J. Mag. Soc, Jpn. 30, 1 (2006).

20) J. A. C. Bland, S. J. Steinmuller, A. Hirohata, and T. Taniyama, in Ultrathin Magnetic Structure IV: Application, edited y J. A. C. Bland and B. Heinrich, Springer, Berlin (2005).

21) H. Kurebayashi, S. J. Steinmuller, J. B. Laloë, T. Trypiniotis, S. Easton, A. Ionescu, J. R. Yates, and J. A. C. Bland, App. Phy. Lett. 91, 102114 (2007).

22) D. A. Papaconstantopoulos, HANDBOOK OF THE BAND STRUCTURE OF ELEMENTAL SOLIDS, PLENUM PUBLISHING CORPORATION, New York, (1986).

23) J.-B. Xia, S.-F. Ren, and Y.-C. Chang, Phy. Rev. B 43, 1692 (1991).

24) S. Honda, T. Kondo, H. Itoh, and J. Inoue, Phys. Rev. B 74, 155329 (2006).

25) M. Zwierzycki, K. Xia, P. J. Kelly, G. E. W. Bauer, and I. Turek, Phy. Rev. B 67, 092401 (2003).

2007 年 10 月 12 日受理, 2008 年 2 月 14 日採録 